\title{
Research on the Puzzlement and Countermeasures of the Application of Southwest Minority Intangible Cultural Heritage in Animation Teaching
}

\author{
Xin Xiao \\ Guilin University of Technology, Guilin, China \\ Email:171518056@qq.com
}

How to cite this paper: Xiao, X. (2021) Research on the Puzzlement and Countermeasures of the Application of Southwest Minority Intangible Cultural Heritage in Animation Teaching. Open Access Library Journal, 8: e8149.

https://doi.org/10.4236/oalib.1108149

Received: November 4, 2021

Accepted: November 22, 2021

Published: November 25, 2021

Copyright $\odot 2021$ by author(s) and Open Access Library Inc.

This work is licensed under the Creative Commons Attribution International License (CC BY 4.0).

http://creativecommons.org/licenses/by/4.0/

\begin{abstract}
This paper analyzes the significance and role of strengthening the application of southwest minority intangible cultural heritage in animation, discusses the problems existing in the application of southwest minority intangible cultural heritage in animation teaching, and puts forward measures and methods to solve these problems, in order to better apply minority intangible cultural heritage to animation teaching and improve students' creative ability.
\end{abstract}

\section{Subject Areas}

Teaching and Learning Technologies

\section{Keywords}

Animation Teaching, Intangible Cultural Heritage, Ethnic Minorities

\section{Introduction}

Southwest minority intangible cultural heritage carries a large number of excellent Chinese traditional culture and art. However, due to the complex geographical environment, relatively separated physical space, strong closeness and relatively backward economic development, the protection, inheritance and wide dissemination of intangible cultural heritage are greatly hindered. Therefore, the inheritance and development of southwest minority intangible cultural heritage need to be solved urgently. However, at present, there are many problems in the animation teaching based on the intangible cultural heritage of ethnic minorities in Southwest China, such as too single teaching methods and weak teachers; Pay 
too much attention to animation skills and ignore the cultivation of creativity; Lack of excavation of life materials of ethnic minorities; Students lack understanding of the intangible cultural heritage of ethnic minorities; The existing curriculum arrangement and training direction of animation major do not match the training objectives of students' cultural literacy. The results are as follows: first, the national characteristics of animation works are not distinct. In recent years, affected by foreign animation films, all fields of China's animation industry have been impacted. In the field of animation education, on the one hand, because students' animation creation aesthetics is affected by foreign animation styles, it is difficult to raise students' creative desire by using Southwest National Intangible Cultural Heritage in animation teaching, Animation Teaching in Colleges and universities cannot allow students to imitate and apply foreign animation styles with low quality, and cannot let students find the positioning of Chinese animation and lose their creative direction under the pressure of foreign animation; On the other hand, due to the higher technical requirements of foreign animation production and software technology, under the influence of foreign animation style, many students pay more attention to animation production and software technology, ignoring the creation of animation content.

Second, there are deficiencies in the innovation of animation teaching methods. At present, the discipline development system of animation specialty in Colleges and universities in China is becoming more and more perfect. Animation teachers have certain cultural literacy and technical ability, but there are deficiencies in the innovation and timeliness of teaching methods, which makes it difficult to implement the southwest national intangible cultural heritage culture in animation creation. Although the traditional stories of southwest national intangible cultural heritage can be integrated into teaching. However, it is difficult to occupy a favorable position in animation teaching. In this case, it is difficult to meet the needs of professional talents for the development of animation in China; Due to the lack of innovation in teaching methods, the intangible cultural heritage of southwest minorities cannot be effectively integrated with domestic animation technology in the application of animation teaching, which hinders the play of southwest minority intangible cultural heritage in animation teaching activities to a certain extent. Therefore, it is of practical significance to combine animation teaching with intangible cultural heritage of southwest ethnic minorities.

\section{The Significance and Function of Strengthening the Application of Southwest Minority Intangible Cultural Heritage in Animation}

The integration of minority intangible cultural heritage into animation teaching is not only conducive to students' understanding of China's minority intangible cultural heritage, but also combines minority intangible cultural heritage with modern animation technology, which also gives new artistic vitality to minority intangible cultural heritage. In the traditional animation teaching, it is often 
centered on the classroom and assisted by teaching materials. In this way, students' creativity and innovation consciousness are lack of cultivation. Using the rich intangible cultural resources of ethnic minorities, let students find creative themes and creative inspiration from the intangible cultural heritage of ethnic minorities, explore design elements, integrate the intangible cultural heritage of ethnic minorities into the training of animation courses, let students experience the unique language symbols of the intangible cultural heritage of ethnic minorities in their daily life, and turn the intangible cultural heritage into design elements. Let students refine the history, technology and characteristics of the intangible cultural heritage of ethnic minorities, combine the patterns, colors and patterns of the intangible cultural heritage with the animation theme, strengthen the nationality of the animation works, and let students no longer stick to the traditional textbook teaching, but more effectively combine the animation works with the intangible cultural heritage of ethnic minorities, It can not only stimulate students' innovation ability, but also exercise students' thinking ability.

In the teaching activities of animation specialty, teachers explain how these animation works learn from intangible cultural heritage culture by analyzing excellent cases, so as to form a unique style, so that students can understand how to absorb the essence of China's minority intangible cultural heritage culture and create unique animation works. In teaching activities, teachers should teach the intangible cultural heritage of China's ethnic minorities, customs, textile skills and other intangible cultural heritage, and let students create animation in groups in combination with the intangible cultural heritage of ethnic minorities. By showing outstanding works of simultaneous interpreting, we can not only arouse students' interest in the culture of ethnic minorities, but also help students help each other and inherit the heritage culture of our excellent ethnic minorities. In addition, the school can set up practical activity courses and arrange students to conduct field research in their spare time, so that students can experience the production of intangible cultural heritage. Enable students to explore China's minority culture in the process of practice, so that students can feel the characteristics of minority culture in different regions, so as to improve students' cognition of China's minority intangible cultural heritage, truly feel the charm of intangible cultural heritage, and make animation works with the characteristics of minority intangible cultural heritage in the form of creation.

In addition, the integration of minority intangible cultural heritage into animation works can make China's minority intangible cultural heritage spread all over the world. There are many ethnic minorities in China. The intangible cultural heritage of ethnic minorities is an important part of Chinese traditional culture. These intangible cultural heritage of ethnic minorities is an inexhaustible source for us to use in the creation of animation works, which can greatly enrich the creative materials of animation works. By introducing the intangible cultural heritage into the teaching of animation courses in animation teaching, teachers integrate the intangible cultural heritage of ethnic minorities into the 
training of animation professionals in Colleges and universities, which can not only enrich the teaching content of animation, but also inherit and protect the non heritage of ethnic minorities and enhance students' national self-confidence.

The intangible cultural heritage of ethnic minorities in Southwest China has rich animation modeling characteristics. Teachers guide students to collect excellent traditional folk literature such as Ethnic Myths, fables and folklores, and lead students to analyze the content and theme sources of ethnic minority animation and integrate the excellent parts into their own animation works. Guide students to observe life, find inspiration from life and create animated characters. Add practical courses to enable students to personally understand local ethnic minority cultures, analyze and compare ethnic cultures in different regions, cultivate students' awareness of ethnic minority cultures, and improve their sense of national pride and cultural identity. On this basis, students can gradually excavate ethnic minority cultural elements for animation creation.

\section{Countermeasure Research and Methods}

\subsection{Absorb the Intangible Cultural Elements of Southwest Ethnic Minorities and Explore the Road of Animation with National Characteristics}

Colleges and universities are the main positions for talent training and cultural inheritance. In view of the influence of foreign animation style and production on the learning of middle school students in China's animation teaching, it is proposed to strengthen the absorption of non heritage elements of southwest ethnic minorities and use them in animation creation and application, so as to create animation works with southwest ethnic characteristics; [1] Strengthen the comprehensive study and in-depth understanding of the intangible cultural heritage of southwest nationalities, formulate the animation teaching mode of the intangible cultural heritage of Southwest Nationalities in line with students' learning interests, so that students can correctly understand the intangible cultural elements of southwest nationalities, rather than simply copy and paste the intangible cultural heritage of Southwest Nationalities, which should be simplified and condensed before use; In the teaching application, actively guide students to pay attention to the innovation of animation content, pay attention to the study of software technology and animation production, fully master all links of animation production, and cultivate animation creators who can innovate and use the intangible cultural elements of Southwest Nationalities and master software skills, so as to provide a new development direction for China's animation creation, At the same time, it provides a new direction for the protection and inheritance of southwest national intangible cultural heritage.

\subsection{Innovate Animation Teaching Methods and Improve the Application of Southwest Minority Intangible Cultural Heritage in Animation Teaching}

First of all, in view of the method problems existing in the application of south- 
west minority intangible cultural heritage in animation teaching, animation teachers should fully realize the role of method innovation in improving southwest minority intangible cultural heritage in animation teaching, and strengthen the learning and understanding of the connotation of southwest minority intangible cultural heritage in the process of formulating new teaching plans, Ensure that the formulation of teaching methods can provide favorable support for the content innovation and talent training of southwest minority intangible cultural heritage in animation teaching, and better reflect the importance of southwest minority intangible cultural heritage; In the process of teaching, animation teachers need to separate cultural factors from software technology, so as to ensure that students can learn animation creation technology as much as possible, and ensure the application of cultural level, so as to provide more comprehensive support for the training mode of animation talents and the integrity of animation methods.

\subsection{Seeking the Participatory Design of Intangible Cultural Heritage Inheritors}

Many intangible cultural heritages of ethnic minorities involve the living customs, folk traditions, historical events and oral skills of ethnic minority people. It is difficult to understand the true meaning of intangible cultural heritage culture through simple imitation. Animation creation without research may produce Cultural Deviation and give wrong guidance to the audience. Therefore, in the early research of animation creation, seeking the participatory design of intangible cultural heritage inheritors can not only more accurately record the culture of ethnic minorities, but also help to show the cultural view of ethnic minorities; It not only helps to show the cultural world dominated by local people, but also helps to see the local people's world from the perspective of outsiders (animators), so as to promote intercultural dialogue [2]. For example, in the animated film $\mathrm{Nu}$ Wa mending the sky, director Qian Yunda led his team to Ximeng Wa Autonomous County to conduct research and record the life of Wa people at that time; In the animated films "ginseng fruit" and "Zhang Fei examines melon", the creative team invited Kunqu artist Liu Yilong to participate in the guidance. The visual image and body movements of the animated characters show strong opera characteristics. The participatory creation of minority intangible cultural heritage inheritors improves the authenticity of national animation. The collaborative innovation of creators and inheritors is an effective path for the activation and exploration of intangible cultural heritage culture, which can realize the creation of animation and the inheritance and innovation of intangible cultural heritage on the premise of authenticity and objectivity.

\subsection{Pay Attention to Refining and Exploring the Contemporary Value of Intangible Cultural Heritage}

General Secretary Xi pointed out: "to carry forward the excellent Chinese traditional culture, we should deal with the relationship between inheritance and cre- 
ative development, and realize the creative transformation and innovative development of Chinese culture." [3] The animated inheritance of intangible cultural heritage is also the "historic" inheritance of intangible cultural heritage [4]. However, there be inopportune or inappropriate elements in the inheritance of intangible cultural heritage, such as backward customs, feudal superstition, animators, and the essence and dross of the historical heritage. In addition, animation creators should start from the needs of the times, make a contemporary interpretation of the "Historicity" of intangible cultural heritage, create the practical value of intangible cultural heritage culture, and inherit and protect intangible cultural heritage by using the development mode of "new form + new value". For example, the animated film "little door god" is based on the theme of New Year pictures, takes the incompatibility between traditional folk elements and the rapid development of modern society as the narrative point, deeply integrates traditional cultural elements, folk elements and real business scenes, and creates a scene with both folk customs and close to real life.

\subsection{Grasp the Balance of Cross-Cultural Creation}

The animation works of the "Chinese School" have strong national characteristics and show the unique charm of Chinese culture to the world audience. Nowadays, in the context of globalization, there are few audience groups of ethnic minority intangible cultural heritage. The animation creation using ethnic minority intangible cultural heritage will inevitably lead to cultural discount and cultural misreading by foreign audiences, which is not conducive to the international promotion of ethnic minority intangible cultural heritage. While retaining Chinese cultural symbols, cultural creators should build values recognized by Eastern and Western audiences in content creation and stimulate the common positive emotions of the audience, so as to promote Chinese culture to go global and obtain the cultural identity of foreign people.

\subsection{Using Online Teaching Methods}

Online teaching can enable more students to obtain rich knowledge. For example, the form of online teaching of teachers of various disciplines adopted by station $\mathrm{B}$ on the network has crossed the obstacles of time and space. That is to solve the problem of the lack of communication mode of minority intangible cultural heritage, and provide a reference paradigm for animation teaching. To inject excellent minority culture into teaching is a breakthrough in animation teaching. Under the premise of ensuring that the intangible cultural heritage can survive without being destroyed, the content of the intangible cultural heritage resources of ethnic minorities is taken as the essence to make animation [5], and the regional culture of ethnic minorities is characterized by its characteristics, cultural customs, distinctive buildings, national costumes, special festivals, handicrafts, etc. Folk dance, spread to the masses in the form of animation, can not only protect the intangible cultural heritage of ethnic minorities, but also achieve the purpose of animation teaching. 


\section{Conclusion}

In short, while developing the intangible cultural heritage of ethnic minorities in Southwest China, we should examine its characteristics in an all-round way, sort out and choose them appropriately, and create animation with local ethnic characteristics. Integrate the cultural elements of southwest ethnic minorities with animation teaching, analyze the characteristics, deeply excavate, and explore the spiritual connotation and artistic forms, so that students can deeply understand the intangible cultural heritage of southwest ethnic minorities, effectively expand the artistic influence of intangible cultural heritage of southwest ethnic minorities, and enhance national pride and cultural identity. On this basis, let students gradually tap the cultural elements of ethnic minorities for animation creation. However, due to the wide variety of intangible cultural heritage of ethnic minorities in Southwest China, the application foundation in animation teaching is weak, and there are still many places worthy of further in-depth study.

\section{Conflicts of Interest}

The author declares no conflicts of interest.

\section{References}

[1] Zhong, L.Q. (2016) The Influence of Chinese Elements on Animation Art from the Perspective of Folk Culture. Popular Literature and Art, 11, 133.

[2] Wang, Y.J. (2019) Representation Strategy and Participatory Design of Ethnographic Animation. National Art, 4, 158-161.

[3] Xi, J.P. (2014) Xi Jinping General Secretary's Speech Series. People’s Publishing House, Beijing.

[4] Jiang, Y.Y. and Huang, X.Y. (2018) Animation's Use and Dissemination of Intangible Cultural Heritage. Film Evaluation, 2, 89-91.

[5] Deng, X. (2018) Animation Teaching Reform of National Culture Injection-Research on the Injection of Local Intangible Cultural Heritage Elements in Hainan. University Education, 5, 117-120. 